\title{
Açaí (Euterpe oleracea Martius) supplementation in the diet during gestation and lactation attenuates liver steatosis in dams and protects offspring
}

\author{
Priscila O. Barbosa ${ }^{1} \cdot$ Melina O. de Souza ${ }^{2} \cdot$ Deuziane P. D. Paiva ${ }^{2} \cdot$ Marcelo E. Silva $^{1,2} \cdot$ Wanderson G. Lima $^{1}$. \\ Giovanna Bermano $^{3} \cdot$ Renata N. Freitas $^{1,2}$ (D)
}

Received: 25 January 2019 / Accepted: 29 June 2019 / Published online: 5 July 2019

(c) Springer-Verlag GmbH Germany, part of Springer Nature 2019

\begin{abstract}
Purpose Maternal high-fat diet affects offspring and can induce metabolic disorders such as non-alcoholic fatty liver disease (NAFLD). New therapeutic strategies are being investigated as way to prevent or attenuate this condition. The objective of this study was to evaluate the effect of açaí supplementation in the maternal high-fat diet on dams and offspring lipid metabolism. Methods Female Fisher rats were divided in four groups and fed a control diet (C), a high-fat diet (HF), an açaí supplemented diet (CA) and a high-fat diet supplemented with açaí (HFA) 2 weeks before mating, during gestation and lactation. The effects of açaí were evaluated in the male offspring after birth (P1) and weaning (P21).

Results HFA reduced relative liver weight, fat and cholesterol liver content in dams and improved liver steatosis as confirmed by histological analyses. HFA increased serum cholesterol and expression of Srebpfl and Fasn genes. In offspring, HFA decreased relative liver weight, and serum cholesterol only in P21. An increase in the Sirt1, Srebpfl and Fasn genes expression was observed in P21.

Conclusions These results suggest that açaí supplementation may attenuate NAFLD in dams and protect offspring from the detrimental effects of lipid excess from a maternal high-fat diet.
\end{abstract}

Keywords Açaí $\cdot$ Euterpe oleracea Martius $\cdot$ High-fat maternal diet $\cdot$ Metabolic programming $\cdot$ Non-alcoholic fatty liver disease

\section{Introduction}

Non-alcoholic fatty liver disease (NAFLD) is characterized by accumulation of triglycerides in hepatocytes. This disease encompasses a spectrum of conditions ranging from simple hepatic steatosis to non-alcoholic steatohepatitis (NASH) characterized by the presence of inflammation, which can progress to cirrhosis or hepatic carcinoma [1].

Renata N. Freitas

renata.freitas@ufop.edu.br

1 Nucleus of Research in Biological Sciences (NUPEB), Federal University of Ouro Preto, Ouro Preto, MG, Brasil

2 School of Nutrition, Federal University of Ouro Preto, Ouro Preto, MG, Brasil

3 Centre for Obesity Research and Education, School of Pharmacy and Life Sciences, Robert Gordon University, Aberdeen, UK
The prevalence of NAFLD in children and adolescents has evidenced the role of maternal nutrition during critical periods of fetal development [2]. Metabolic programing is a process by which maternal lifestyle (including diet) promotes modifications in the uterus environment or milk composition that can trigger several changes in the sequence of events, in the gestational or lactation periods, leading to metabolic disorders in the offspring [3]. The molecular mechanisms and pathways involved are not well understood but some studies have pointed epigenetic changes as having a pivot role in the process [4]. This is a current and extremely relevant concept due to the pandemic of metabolic diseases, such as diabetes, obesity and systemic arterial hypertension [5] that might be partially explained by metabolic programming. High-fat maternal diet has been widely used in the literature to induce NAFLD in experimental animal models and the consumption of such diet reflects the current world scenario in which excessive lipid intake may contribute to rise of liver diseases in the population $[6,7]$. Over the last decade, considerable 
progress has been made in understanding how the excess of lipid intake via maternal diet alters metabolic pathways in the uterus, predisposing the fetus to accumulation of fat in the liver, and consequently the development of NAFLD in adult life [8].

Sirtuins, a family of proteins dependent on intracellular levels of NAD+, stood out because of their important role in energy metabolism [9]. Sirtuin 1 (SIRT1) has been extensively studied due to its involvement in several metabolic processes: it deacetylates the sterol regulatory element-binding protein (SREBPs) promoting inhibition of its activity [10]. SREBPs are transcription factors and three different isoforms, SREBP-1a, SREBP-1c and SREBP-2, are present in mammalian cells. SREBPs directly activate the expression of more than thirty genes related to the synthesis and uptake of cholesterol, fatty acids, triglycerides and phospholipids, in addition to increase the expression of genes involved in the generation of NADPH, a necessary cofactor used in anabolic reactions such as lipid metabolism [11]. In general, SREBP-1 regulates transcription of lipogenic genes, ranging from genes involved in fatty acid biosynthesis to gene regulation of the enzyme fatty acid synthase (FASN). Studies evaluating the effect of maternal diet have shown that the excess of lipids can reduce the expression and activity of SIRT1 in the liver of mothers and offspring, causing alterations in liver metabolism and promoting fat accumulation $[12,13]$.

Under normal physiological conditions, fat accumulates in adipose tissue and not in the liver; however, lipid accumulation in the liver can occur when there are alterations between mobilization and lipid oxidation. Studies have shown that excess of fatty acids may promote mitochondrial dysfunction and reduce oxidative capacity of mitochondria in mothers and their offspring [14]. The lipid influx, in addition to compromised oxidative capacity of the mitochondria, can result in accumulation of partially oxidized lipid products and generation of additional reactive oxygen species (ROS), which can overwhelm cell defenses leading to oxidative stress [15]. In this sense, mitochondrial uncoupling protein 2 (UCP2) has emerged as a potential regulator of hepatic steatosis. UCP2 allows the transfer of anions from the inner mitochondrial membrane to the cytosol and the return transfer of protons from the outer to the inner membrane [16]. It is, therefore, possible that UCP2 is capable of attenuating hepatic steatosis through the control of ROS production [17].

Together with studies that seek to better understand changes that occur in the womb and precede development of metabolic disorders, the search for new therapeutic targets and the introduction of foods with a potential beneficial effect on metabolism have emerged in the scientific field. The most common compound studied is resveratrol, a polyphenol naturally found in purple grapes and widely accepted as chemoprotective agent [18]. In models of hepatic steatosis induced by high-fat maternal diet, administration of resveratrol was shown to efficiently reduce plasma and hepatic storage of triglycerides, both studies through SIRT1 upregulation in offspring [10, 19-21]. Moreover, other polyphenols such as flavonoids, flavonols, anthocyanidins, flavonones, and isoflavones have been studied as potential agents for the prevention and treatment of NAFLD [21]. Therefore, the activation of SIRT1 by polyphenols would be beneficial for the prevention and treatment of NAFLD.

Açaí (Euterpe oleracea Martius), an Amazon fruit, with a high content of phenolic compounds of the class of anthocyanins, mainly cyanidin-3-rutinoside, cyanidin-3-glycoside, cyanidin-3-sambubioside, peonidin-3-glycoside and peonidin-3-rutinoside [22] has been the subject of research seeking to evaluate its potential beneficial effect on health. Recent work evaluating the effect of açaí on NAFLD pathology demonstrated a hepatoprotective action of this fruit by modulating the expression of genes involved in adiponectin signaling, lipogenesis and oxidation of fatty acids [23, 24]. However, little is known about the effect of açaí on the molecular mechanisms involving hepatic and lipid metabolism in NAFLD induced by high-fat maternal diet and its effect on offspring. Our hypothesis is that, due to its high content of polyphenols, açaí supplementation in dams' diet 2 weeks before mating and during gestation and lactation protects them and their offspring against NAFLD induced by high-fat diet. The aim of this study was, therefore, to evaluate pathways involved in the development of NAFLD in rats, which may be modified by supplementing a high-fat diet with $2 \%$ of açaí pulp during gestation and lactation. Moreover, the effect of such intervention was studied in postnatal and post-weaning offspring.

\section{Materials and methods}

\section{Açaí pulp}

Pasteurized frozen açaí pulp without colorants or preservatives was obtained in a single lot (07/2016) from Icefruit Comércio de Alimentos Ltda (Tatui, São Paulo, Brazil). Chemical analysis of the pulp showed moisture content of 90\%, 3.9-g lipids, 2.3-g total carbohydrate, 0.9-g protein, 2.3-g insoluble fiber and 0.4-g soluble fiber per $100 \mathrm{~g}$ of pulp.

Polyphenol content of açaí pulp was determined using Folin-Ciocalteu reagent as described previously [25]. A standard curve was constructed using different concentrations of gallic acid for quantifying total polyphenols and values were expressed in $\mathrm{mg}$ of gallic acid equivalent (GAE) in $100 \mathrm{~g}$ of açaí pulp. The açaí pulp used in this study presented $549.5 \mathrm{mg}$ GAE$/ 100 \mathrm{~g}$. The content of anthocyanins was also 
measured as reported by Giust and Wrolstad [26]. The assay consists of the $\mathrm{pH}$ differential method and the values were expressed as cyanidin-3-glucoside equivalents, $\mathrm{mg} / \mathrm{L}$ of pulp. The total anthocyanin of açaí pulp was $6.5 \mathrm{mg} / \mathrm{L}$.

\section{Animals and diets}

All procedures used in this study were approved by the Ethics Committee in Animal Research of the Federal University of Ouro Preto (Protocol No. 2015/15). Thirty-two female Fischer rats ( 90 days of age) were obtained from the Laboratory of Experimental Nutrition at the School of Nutrition of the Federal University of Ouro Preto (Minas Gerais, Brazil). Animals were divided into four groups receiving different diets: control diet (C), high-fat diet (HF, $60 \%$ of total calories as fat, been $53 \%$ saturated fat, $6 \%$ soybean oil and $1 \%$ cholesterol), control diet supplemented with açaí pulp (CA, control diet plus $2 \%$ of açaí pulp) or high-fat diet supplemented with $2 \%$ of açaí pulp (HFA). Control diet and high-fat diet were based on the AIN-93G diet, with some modifications according to previous studies [23, 27-29]. All animals were maintained in a standard environment, $23{ }^{\circ} \mathrm{C} \pm 2{ }^{\circ} \mathrm{C}, 55 \%$ humidity and 12 -h light/darkness cycle, with food and water provided ad libitum. Initially, animals were fed with the respective experimental diets for 2 weeks. After one week, we evaluated the food intake. After 2 weeks in the experimental diets, the mating was performed with a male rat together with two females for one week. After the mating period, females were separated and housed in individual cages to allow the natural progression of gestation, while continuing to receive the allocated diet during gestation and lactation. The dams' body weight was measured in the first week, pre-mating week, and in the day of euthanise. At birth, some of the male pups $(n=7)$ were anesthetised under isoflurane and euthanised by decapitation (postpartum offspring, P1); whereas, the rest of the pups were kept, six per dam, to guarantee homogeneous growth of the litters. At weaning, the dams and the remaining offspring male (P21) were euthanised as above. Male pups were chosen as to reflect the higher incidence of NAFLD in male population [30] and seven male pups of each group were randomly selected for all the analyses.

\section{Collection of blood and tissue samples}

At the end of the experimental period, dams and P21 $(n=7$ per group) were anesthetised under isoflurane, after 12-h fasting, and killed by total blood collection from the brachial plexus. Blood samples were collected and centrifuged at $3000 \mathrm{~g}$ for $15 \mathrm{~min}$ at room temperature. Serum was then removed and stored at $-80{ }^{\circ} \mathrm{C}$ for further analyses. Livers from dams, P1 and P21 were collected, washed with cold saline solution and weighed. The small hepatic lobe was submerged in liquid nitrogen and immediately stored at $-80{ }^{\circ} \mathrm{C}$ for gene and protein expression analyses.

\section{Blood chemistry}

Enzymes activities for aspartate aminotransferase (AST) and alanine aminotransferase (ALT) were measured in serum samples using a fixed time kinetic reaction following manufactures' instructions (Labtest, Lagoa Santa, Brazil). The levels of serum triglycerides (TG) and total cholesterol (TC) were determined using a colorimetric assay acquired from Labtest (Lagoa Santa, Brazil) following manufacturer's instructions.

\section{Lipid liver content}

Hepatic lipids were extracted from liver tissue using a chloroform/MeOH solution $(2: 1, \mathrm{v} / \mathrm{v})$, as described by Folch et al. [31]. The content of total lipids in the liver was quantified gravimetrically by evaporation of the solvents and dissolution of the dried lipids in $500 \mu \mathrm{l}$ of isopropanol. Concentrations of TG and TC were determined colorimetrically using TG and TC assay kits (Labtest, Lagoa Santa, MG, Brazil).

\section{Histological examination}

Liver smallest lobe was cut and fixed in $4 \%$ formalin-buffered solution. After fixation, the tissues were cleared and processed in decreasing concentrations of alcohol and sealed in paraffin. Through a semi-automatic microtome, the paraffin sections were laminated $(4 \mu \mathrm{m})$, stained with hematoxylin and eosin (H\&E) and photographed at $40 \times$ magnification (Leica Application Suite, Germany). Liver histology was examined using 15 images obtained at random from the tissue and classified for the degree of macro-vesicular steatosis. The degree of hepatic steatosis was assessed according to scores defined in previous studies and based on the percentage of hepatocytes that present accumulation of fat, being absent $<5 \%$; mild between 6 and 33\%; moderated between 34 and $66 \%$; marked $>66 \%$ of affected hepatocytes [32].

\section{Quantitative reverse transcription polymerase chain reaction analysis}

Total RNA extraction was performed from 10 to $20 \mathrm{mg}$ of frozen liver tissue using TRI Reagent ${ }^{\circledR}$ Solution (Invitrogen, UK) following the manufacturer's instructions. RNA purification was checked by the ratio A260/A280, utilizing a UV/VIS spectrophotometer (Thermo Spectronic, Helios $\gamma)$. One hundred ng of RNA was transcribed to cDNA by RT-PCR using Super Script III Reverse Transcriptase (Invitrogen, UK) and random hexamers as primers (Promega, 
UK). The cDNA product was used as template in the quantitative real-time PCR (qPCR) reaction performed with SYBR Green PCR Master Mix kit (Primer design, UK), as recommended by the manufacturer. Reactions were done in duplicate and each reaction had a negative control with water added instead of template. The sequences of oligonucleotide primers for qPCR are noted in Table 1. mRNA levels were analyzed using comparative $\mathrm{Ct}$ method and target gene expression was related to the expression of the house keeping gene, $\beta 2$ microglobulin.

\section{Western blotting}

Frozen liver samples were homogenized in Cell Lysis buffer (Cell Signaling Technology, Inc. Danvers, MA, USA) containing 40-mM Tris-HCl (pH 7.5), 300-mM NaCl, 2-mM $\mathrm{Na}_{2}$ EDTA, 2-mM EGTA, 2\% Triton, 5-mM sodium pyrophosphate, 2-mM $\beta$-glycerophospate, 2-mM Na${ }_{3} \mathrm{VO}_{4}, 2 \mu \mathrm{g} /$ $\mathrm{ml}$ leupeptin, a cocktail of protease inhibitors (Sigma, St Louis, MO) and 1-mM PMSF following the manufacturer's instructions. Liver homogenates were centrifuged at $13,000 \mathrm{~g}$ for $15 \mathrm{~min}$ at $4{ }^{\circ} \mathrm{C}$ and supernatants were aliquoted and stored at $-80^{\circ} \mathrm{C}$. Protein concentration was measured by DC ${ }^{\mathrm{TM}}$ protein assay (Bio-Rad, UK) following kit guidelines. Thirty $\mu$ g of total protein for pulled samples from each experimental group was loaded per lane (pulled samples were run in duplicate per gel), subjected to $9 \%$ SDSPAGE, and transferred to polyvinylidene fluoride (PDVF) membranes (GE Healthcare, USA) by wet transfer at $100 \mathrm{~V}$ for $1 \mathrm{~h}$ using a Mini Trans-Blot cell system (Bio-Rad Laboratories, Hercules, CA). Membranes were blocked using 4\% non-fat dry powered milk dissolved in Tris-buffered saline tween-20 (TBST) for $1 \mathrm{~h}$ at room temperature. The primary antibodies for SIRT1 (ab110304), SREBP1 (ab28481) and beta actin (ab8227) (all antibodies obtained from Abcam, Cambridge, UK) were used according to the manufacturer recommended dilutions (1:2000 for SIRT1 and SREBP, 1:10,000 for Actin) and were incubated overnight at $4{ }^{\circ} \mathrm{C}$. The membranes were then washed three times for $5 \mathrm{~min}$ with TBST, before incubation for $1 \mathrm{~h}$ at room temperature with secondary peroxidase conjugated goat anti-rabbit (ab6721, Abcam, Cambridge, UK) or goat anti-mouse (ab205719,
Abcam, Cambridge, UK) diluted at 1:5000 in 4\% non-fat dry milk-TBST. Membranes were washed as before, and the bound antibodies were visualized by enhanced chemiluminescence (ECL) SuperSignal® (ThermoScientific, USA) using a peqLab Fusion FX7 system (VilberLourmat). Beta actin levels were used as control and levels of SIRT1 and SREBP1 were related to beta actin levels. Image $J$ software was used to calculate band intensity.

\section{Statistical analysis}

Statistical analysis was performed using GraphPad Prism 6 for Windows (GraphPad Software, San Diego, CA). All data were tested for normality using the Kolmogorov-Smirnov test. Parametric data from the four groups were analyzed by one-way ANOVA followed by Tukey test to detect differences between the groups and expressed as mean \pm standard deviation (SD). Non-parametric data (western blotting) or semi-quantitative analyses (histology data) were compared using Wilcoxon and Kruskal-Wallis, respectively. The data were presented as median and range (minimum and maximum values). Data from two groups were compared by unpaired Student's $t$-test. Results were considered statistically significant for $p$ values $<0.05$.

\section{Results}

\section{Dams}

\section{Effect of dietary intervention on body weight, tissue weight and food intake}

The different experimental groups did not present significant changes in body weight in the initial and pre-gestational period. However, at the end of the study, rats receiving HFA had significantly greater body weight $(19 \%, p=0.0128)$ than the $\mathrm{C}$ group (Table 2). Liver weight was also measured at the end of experiment (Table 2): HF group showed a significant increase in the total organ size compared to $\mathrm{C}$ $(46 \%, p=0.0007)$ and CA $(73 \%, p<0.0001)$ groups, while HFA presented an increase in relation to CA group (42\%,
Table 1 Sequence of oligonucleotides

\begin{tabular}{lll}
\hline Gene & Forward primer $\left(5^{\prime}-3^{\prime}\right)$ & Reverse primer $\left(5^{\prime}-3^{\prime}\right)$ \\
\hline Sirt 1 & CTGTTTCCTGTGGGATACCTGACT & ATCGAACATGGCTTGAGGATCT \\
Srebf 1 & CCCAGGGCAGCTCTGTACTCC & AAGCTGTCCCGCAGGTA \\
Fasn & CTTGGGTGCCGATTACAACC & GCCCTCCCGTACACTCACTC \\
Ucp 2 & GGTAAAGGTCCGCTTCCAGG & GCAAGGGAGGTCGTCTGTCA \\
$\beta 2$-microglobulin & TGACCGTATCTTTCTGGTG & ATTTGAGGTGGGTGGAACTG \\
\hline
\end{tabular}

Sirt1 sirtuin 1, Srebf1 sterol regulatory element-binding protein 1, Fasn fatty acid synthase, Ucp2 uncoupling protein 2 
Table 2 Body and liver weight, serum lipid profile, liver function, liver lipid content, and food intake of dams

\begin{tabular}{lcccc}
\hline & $\mathrm{C}$ & $\mathrm{HF}$ & $\mathrm{CA}$ & $\mathrm{HFA}$ \\
\hline Initial body weight $(\mathrm{g})$ & $210.1 \pm 8.83$ & $210.4 \pm 10.48$ & $205.4 \pm 8.35$ & $218.9 \pm 12.84$ \\
Pre-Gestational body weight $(\mathrm{g})$ & $215.4 \pm 11.16$ & $220.7 \pm 13.62$ & $212.1 \pm 8.49$ & $226.5 \pm 15.06$ \\
Final body weight $(\mathrm{g})$ & $213.1 \pm 20.78$ & $230.9 \pm 12.61$ & $237.7 \pm 27.63$ & $255.6 \pm 29.68^{\#}$ \\
Liver weight (g) & $7 \pm 1.17$ & $10.23 \pm 2.89^{\# *}$ & $5.90 \pm 0.52$ & $8.39 \pm 0.99^{*}$ \\
Relative liver weight & $3.33 \pm 0.73$ & $4.45 \pm 1.03^{\# *}$ & $2.53 \pm 0.55$ & $3.30 \pm 0.34^{\S}$ \\
Total cholesterol (mmol/l) & $2.96 \pm 0.74$ & $3.6 \pm 1.69$ & $2.23 \pm 0.68$ & $5.52 \pm 1.66^{\# * \S}$ \\
Triglyceride (mmol/l) & $1.14 \pm 0.49$ & $0.93 \pm 0.38$ & $0.66 \pm 0.17$ & $0.83 \pm 0.19$ \\
AST (U/l) & $15.23 \pm 4.81$ & $22.63 \pm 3.1^{\#}$ & $20.69 \pm 3.72$ & $23.11 \pm 3.68^{\#}$ \\
ALT (U/l) & $23.13 \pm 7.4$ & $62.11 \pm 20.88^{\# * *}$ & $24.61 \pm 7.54$ & $60.54 \pm 14.2^{\# *}$ \\
Liver fat (mg/g) & $98.62 \pm 37.46$ & $214.9 \pm 71.8^{\# *}$ & $56.79 \pm 18.16$ & $117.5 \pm 45.62^{\S}$ \\
Liver cholesterol (mg/g) & $3.75 \pm 0.4$ & $28.3 \pm 4.16^{\# *}$ & $3.36 \pm 0.33$ & $17.21 \pm 6.67^{\# * \S}$ \\
Liver triglyceride (mg/g) & $19.45 \pm 13.36$ & $31.39 \pm 4.51^{*}$ & $18.08 \pm 2.67$ & $22.37 \pm 7.84$ \\
Food intake (g/d) & $13.82 \pm 1.36$ & $9.66 \pm 1.15^{\# *}$ & $14.73 \pm 1.14$ & $10.91 \pm 0.67^{\# *}$ \\
Caloric intake (kj/d) & $229.82 \pm 22.59$ & $217.85 \pm 26.08$ & $240.03 \pm 18.06$ & $242.38 \pm 14.95$ \\
\hline
\end{tabular}

$p<0.05:{ }^{\#}$ versus $\mathrm{C}$, ${ }^{*}$ versus $\mathrm{CA}$ and ${ }^{\S}$ versus HF

$C$ control diet, $H F$ high-fat diet, $C A$ açaí diet, $H F A$ high-fat açaí diet. The results are shown as the mean $\pm \mathrm{SD}$ ( $n=7$ dams per group). One-way ANOVA followed by a Tukey post hoc test $p=0.0088$ ). However, when evaluating the relative liver weight, a statistically significant reduction $(25 \%, p=0.0277)$ was observed in the HFA group in comparison to HF. HF group presented an increase in relative liver weight in relation to $\mathrm{C}(34 \%, p=0.0331)$ and $\mathrm{CA}(76 \%, p=0.0002)$ groups. Regarding the food intake, the supplementation with $2 \%$ of açaí pulp did not affect the caloric intake of the dams (Table 2).

\section{Effect of dietary intervention on serum lipid profile and hepatic function}

Dams fed a HFA presented a significant increase in total cholesterol when compared to C $(86 \%, p=0.0049)$, HF $(53 \%$, $p=0.0492)$ and CA (147\%, $p=0.0004)$ groups; whereas, no change was observed in serum triglyceride levels (Table 2).

The activities of AST and ALT were determined in serum as biomarkers of the extent of hepatic damage (Table 2). $\mathrm{HF}$ and HFA groups showed a significant increase (48\%, $p=0.008$ and $51 \%, p=0.0045$, respectively) in AST when compared to the $\mathrm{C}$ group; whereas, ALT activity was significantly increased in the $\operatorname{HF}(168 \%, p=0.0001$ versus C group; $152 \%, p=0.0002$ versus CA group) and HFA groups $(161 \%, p=0.0002$ versus group $C ; 146 \%, p=0.0003$ versus CA group).

\section{Effect of dietary intervention on liver lipid content}

The content of total fat, cholesterol and triglyceride in the liver was evaluated to assess the extent of NAFLD; the results are presented in Table 2. A significant increase in total fat content was observed in the HF group in relation to $\mathrm{C}(117 \%, p=0.0006)$, CA $(278 \%, p<0.0001)$ and HFA $(82 \%, p=0.004)$. Interestingly, CA group showed a decrease in fat liver content even if it did not reach statistical difference compared to $\mathrm{C}$ group; whereas HFA did not induce an increase in fat liver content as the HF diet did. Hepatic cholesterol levels were higher in the $\operatorname{HF}(654 \%, p<0.0001$ versus $\mathrm{C} ; 742 \%, p<0.0001$ versus CA) and HFA (358\%, $p<0.0001$ versus $C ; 412 \%, p<0.0001$ versus CA), but the HFA group presented lower values in relation to the HF group $(36 \%, p=0.0001)$. Liver triglyceride content in the HF group was also significantly higher than that observed in the CA group $(61 \%, p=0.0268)$.

\section{Effect of dietary intervention on liver steatosis grade}

To evaluate the effect of the different diets on accumulation of lipids and degree of steatosis in the liver, microscopic analysis was performed. Histological analysis revealed that the HF group had a higher grade of steatosis (moderate and marked), whereas the HFA group had an attenuation of steatosis when compared with HF (Fig. 1a). Scoring of the degree of steatosis confirmed the presence of moderate to marked steatosis in the liver of dams fed a HF diet which was reduced to mild-moderate $(p<0.01)$ by açaí supplementation to HF diet (Fig. 1b).

\section{Effect of dietary intervention on gene expression involved in lipid metabolism}

To determine the potential metabolic pathways by which açaí could improve hepatic fat accumulation, the expression of genes involved in lipid metabolism was assessed 

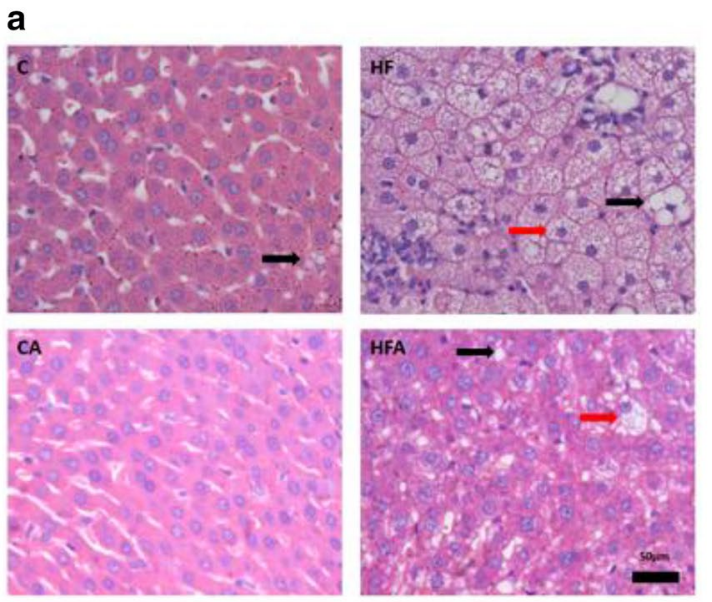

Fig. 1 a Representative histological sections of the liver of dams fed with a control diet (C), high-fat diet (HF), açaí diet (CA) and high-fat supplemented with açaí (HFA), stained with hematoxylin and eosin. Black arrow shows macrosteatosis and red arrow shows microsteato-

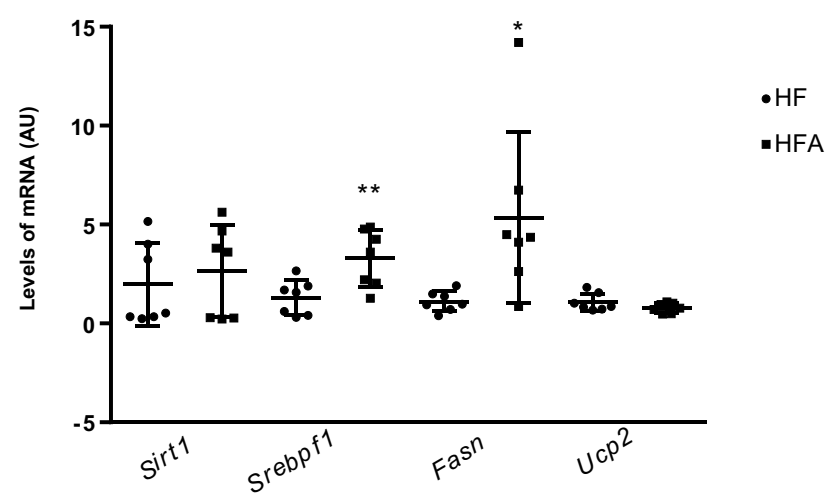

Fig. 2 mRNA abundance for genes related to lipid metabolism in the liver of dams relative to beta-2-microglobulin. $H F$ high-fat diet; $H F A$ high-fat açaí diet, Sirt1 sirtuin 1, Srebfl sterol regulatory elementbinding transcription factor 1, Fasn fatty acid synthase, Ucp 2 uncoupling protein 2 . The results are shown as the mean $\pm \mathrm{SD}(n=7$ dams per group). Analyses by Student's $t$ test. * $p<0.05$; ** $p<0.01$

(Fig. 2). Sirtl mRNA abundance was higher in the HFA group compared to HF group, but no statistically significant differences were found. Surprisingly, the HFA group showed an increase in the relative expression of Srebfl (threefold change, $p=0.0092$ ) and Fasn (fourfold change, $p=0.0241$ ) genes when compared to the HF group.

\section{Effect of dietary intervention on protein levels}

Western blot analysis did not show significant differences in SIRT1 protein levels (Fig. 3a) even if a trend for increased levels in the HFA group could be observed. Although gene expression showed an increase in Srebpfl b

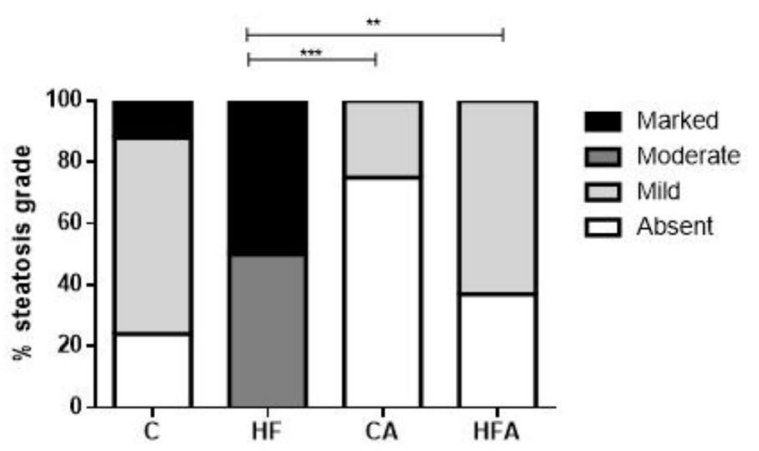

sis. The images were photographed at a magnification of $400 \times$. Bar Scale $=50 \mu \mathrm{m} ; \mathbf{b}$ Grade of hepatic steatosis of dams $(n=7$ dams per group). Value of $p<0.05$ was considered statistically significant for the Kruskal-Wallis. $* *<0.01, * * *<0.005$

in the liver of the dams fed a HFA diet, protein level did not show statistical difference compared to levels in the HF group (Fig. 3b).

\section{Offspring}

\section{Effect of dietary intervention on body and tissue weight}

The effect of a high-fat diet supplemented or not with açaí during gestation on offspring was investigated in pups euthanised 1 day after birth (P1). Body weight did not change between groups (Table 3); whereas, when considering the absolute and relative weight of the liver, the pups HFA-P1 showed a decrease of $27 \%$ in organ size and $33 \%$ in relative weight $(p=0.0088$ and $p=0.0126$, respectively; Table 3) compared to HF-P1 group. Similarly, the effect of the different diets during gestation and lactation was assessed in pups culled at the end of the lactation period (P21). An increase in the body weight of pups from HF-P21 $(40 \%, p=0.0067$ versus CA-P21) and HFA-P21 $(25 \%, p=0.0343$ versus C-P $21 ; 60 \%, p<0.0001$ versus CA-P21) (data shown in Table 3) was observed. The absolute liver weights were also measured at the end of the experiment and pup livers showed an increase from HF-P21 $(47 \%, p=0.0002$ versus C-P21; 59\%, $p<0.0001$ versus CA-P21) and HFA-P21 $(40 \%, p \leq 0.0015$ versus C-P21; $51 \%, p=0.0002$ versus CA-P21). Açaí supplementation reduced the relative weight of the liver by $17 \%$ ( $p=0.0263$, HFA-P21 versus HF-P21), whereas feeding a HF diet induced an increase of $35 \%$ in relative liver weight (Table 3, $p=0.0006$, HF-P21 versus C-P21). 
a
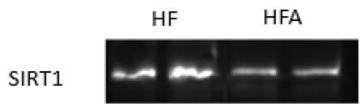

HF HFA

Actin
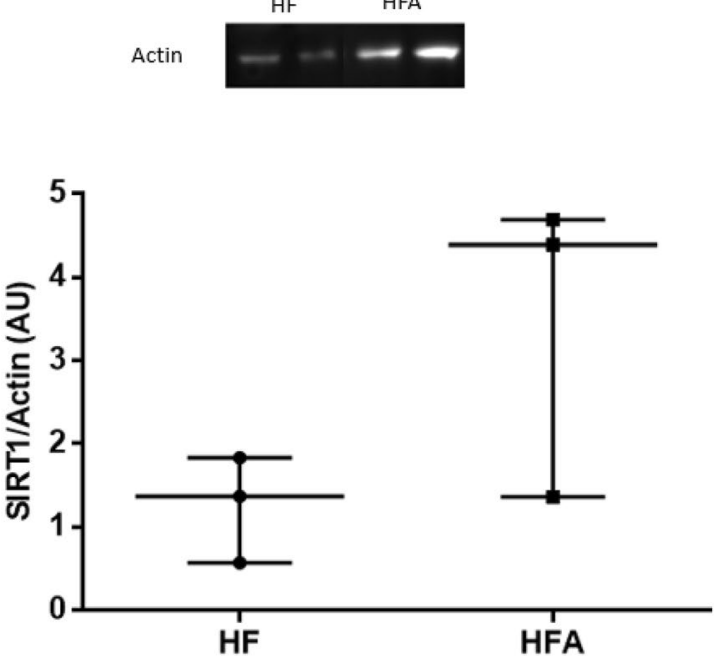

Fig. 3 Western blotting for SIRT1 (a) and SREBP1 (b) of dams. Graphs represent data from Western blotting quantification. $H F$ highfat diet and HFA high-fat supplemented with açaí. Data are shown as b
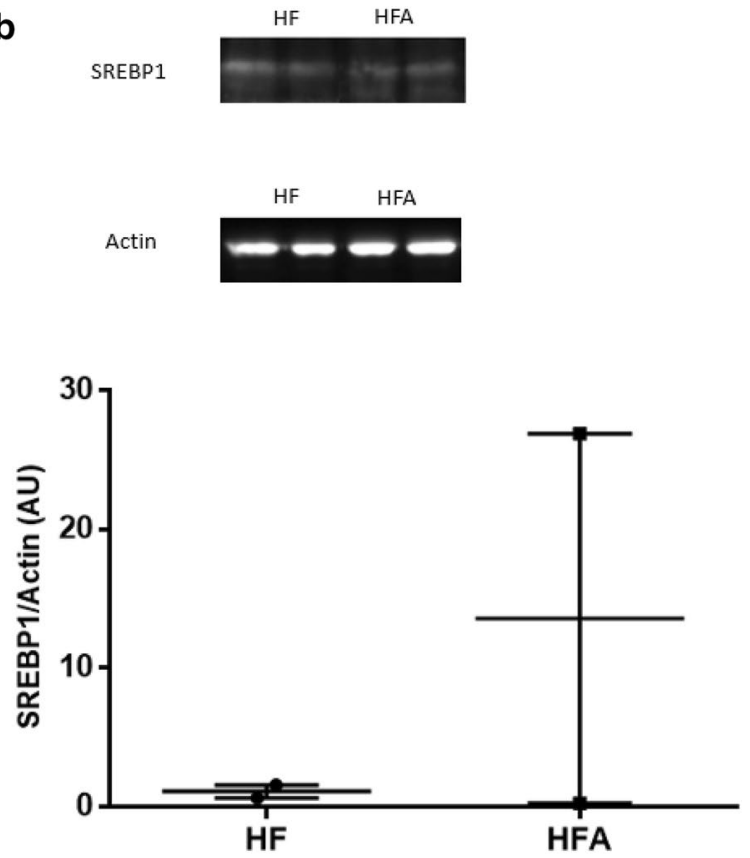

median and range (minimum and maximum value) $(n=7$ dams per group). Value of $p<0.05$ was considered statistically significant for the Kruskal-Wallis

Table 3 Body and liver weight of offspring P1 and P21

\begin{tabular}{|c|c|c|c|c|c|c|}
\hline & \multicolumn{2}{|l|}{ Pups-P1 } & \multicolumn{4}{|l|}{ Pups-P21 } \\
\hline & $\mathrm{HF}$ & HFA & $\mathrm{C}$ & $\mathrm{HF}$ & CA & HFA \\
\hline Body weight (g) & $5.43 \pm 1.07$ & $5.93 \pm 0.59$ & $30.49 \pm 3$ & $33.67 \pm 5.8^{*}$ & $23.96 \pm 4.43$ & $38.36 \pm 7.46$ *\# \\
\hline Liver weight (g) & $0.296 \pm 0.02$ & $0.217 \pm 0.06^{\S}$ & $1.11 \pm 0.14$ & $1.64 \pm 0.26^{\# *}$ & $1.03 \pm 0.21$ & $1.56 \pm 0.23^{\# *}$ \\
\hline Relative liver weight & $5.65 \pm 1.14$ & $3.75 \pm 1.28^{\S}$ & $3.67 \pm 0.54$ & $4.96 \pm 0.89^{\#}$ & $4.32 \pm 0.38$ & $4.1 \pm 0.25^{\S}$ \\
\hline
\end{tabular}

$p<0.05^{\#}$ versus $\mathrm{C},{ }^{*}$ versus CA and ${ }^{\S}$ versus HF

$C$ control diet, $H F$ high-fat diet, $C A$ açaí diet, $H F A$ high-fat açaí diet. Litter size six per dam. The results are shown as the mean \pm SD $(n=7$ pups per group). One-way ANOVA followed by a Tukey post hoc test

\section{Effect of dietary intervention on lipid profile and hepatic function}

The effect of the different maternal diets on lipid metabolism was evaluated by measuring serum levels of cholesterol and triglycerides (Table 4). Pups HF-P21 presented, after gestation and lactation, a significant increase in serum cholesterol in relation to C-P21 $(58 \%, p=0.0004)$ and CA-P21 $(48 \%, p=0.0018)$ groups, whereas HFA-P21 group induced a significant decrease in cholesterol levels $(57 \%, p<0.0001)$ when compared to HF-P21 group. No differences were observed for triglyceride concentrations among the different diets.

The activities of AST and ALT enzymes were also determined in the pups' serum after weaning (Table 4) and no difference was found between groups.

\section{Effect of dietary intervention on liver lipid content}

To assess the effect of maternal diet on promoting early changes in liver dynamics, lipid metabolism, total content of fat, cholesterol and triglyceride levels were evaluated in the liver of offspring after the lactation period (Table 4). No significant differences were found in liver fat values between groups. HF-21 and HFA-P21, during gestation and lactation, induced an increase in total cholesterol concentration in the liver when compared to C-P21 $(144 \%, p<0.0001$ versus HF-P21; 134\%, $p<0.0001$ versus HFA-P21) and CA-P21 $(134 \%, p<0.0001$ versus HF-P21; 124\%, $p<0.0001$ versus HFA-P21). Regarding the triglycerides liver content, açaí supplement in control diet was able to prevent the increase in the triglycerides after the lactation period (Table 4). CA-P21 group 
Table 4 Body and liver weight, serum lipid profile, liver function and liver lipid content of P21

\begin{tabular}{lcccc}
\hline & C & HF & CA & HFA \\
\hline Total cholesterol (mmol/l) & $4.22 \pm 0.51$ & $6.7 \pm 1.88^{* *}$ & $4.52 \pm 0.77$ & $3.87 \pm 0.41^{\S}$ \\
Triglyceride (mmol/l) & $1.2 \pm 0.86$ & $0.96 \pm 0.66$ & $1.24 \pm 0.84$ & $1.24 \pm 0.28$ \\
AST (U/l) & $96.34 \pm 10.17$ & $103 \pm 17.11$ & $98.22 \pm 7.21$ & $94.11 \pm 10.43$ \\
ALT (U/l) & $29.11 \pm 5.63$ & $32.26 \pm 14.96$ & $23.17 \pm 4.36$ & $37.43 \pm 9.26$ \\
Liver fat (mg/g) & $63.89 \pm 37.69$ & $88.39 \pm 28.63$ & $71.48 \pm 7.28$ & $81.89 \pm 18.94$ \\
Liver cholesterol (mg/g) & $4.82 \pm 1.35$ & $11.79 \pm 3.58^{\# *}$ & $5.04 \pm 0.45$ & $11.28 \pm 2.05^{\# *}$ \\
Liver triglyceride $(\mathrm{mg} / \mathrm{g})$ & $22 \pm 7.26$ & $26.42 \pm 6.40^{*}$ & $14.13 \pm 4.84$ & $26.88 \pm 7.76^{*}$ \\
\hline
\end{tabular}

$p<0.05:{ }^{*}$ versus $\mathrm{C}$, *versus $\mathrm{CA}$ and ${ }^{\S}$ versus HF

$C$ control diet, $H F$ high-fat diet, $C A$ açaí diet, $H F A$ high-fat açaí diet, $A S T$ aspartate aminotransferase, $A L T$ alanine aminotransferase. The results are shown as the mean $\pm \mathrm{SD}(n=7$ pups per group). One-way ANOVA followed by a Tukey post hoc test presented reduction in liver triglycerides when compared to HF-P21 and HFA-P21 groups $(87 \%, p=0.0077$ and $90 \%, p=0.0055$, respectively).

\section{Effect of dietary intervention on liver steatosis grade}

Through histology of P21 livers (Fig. 4a), it was possible to observe that HF-P21 had more lipid droplets compared to any other group. In relation to degree of steatosis, HF-P21 group presented a steatosis degree (mild to moderate, Fig. 4b) more pronounced than in CA-P21 and HFA-P21 groups (absent to mild). HFA-P21 group presented a lower degree of steatosis, endorsing the protective effect of açaí in relation to accumulation of hepatic lipids.

\section{Effect of dietary intervention on expression of genes involved in lipid metabolism}

To identify some of the potential molecular pathways involved in lipid metabolism and affected by a diet supplemented with açaí during the gestation and lactation process, gene expression was assessed in P1 and P21 offspring, respectively. No statistically significant differences were observed in the gene expression of P1 (Fig. 5a).

Similarly, the expression of lipid metabolism genes was assessed in the liver from pups after the lactation period (Fig. 5b). Expression of Sirtl (0.5-fold change, $p=0.0168$ ), Srebf1 (fourfold change, $p=0.0274$ ) and Fasn (fivefold times, $p=0.004$ ) was increased in the HFA-P21 liver when compared to HF-P21. No significant differences were found in $U c p 2$ gene expression (Fig. 5b). a
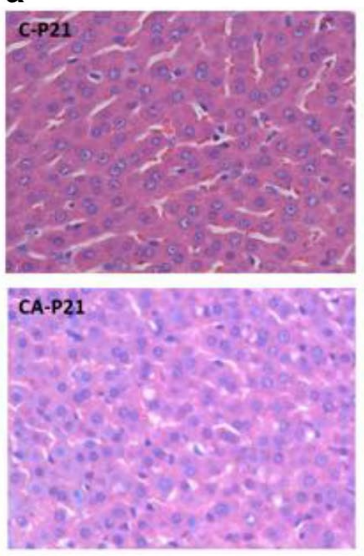
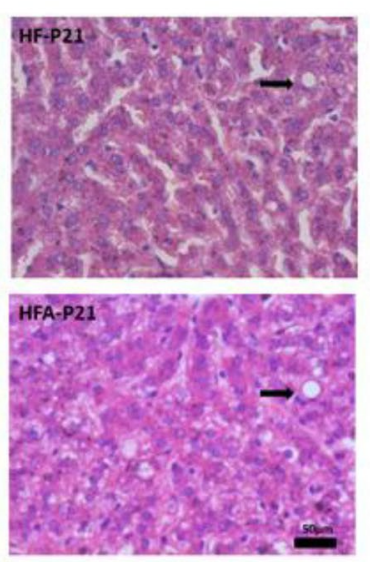

b

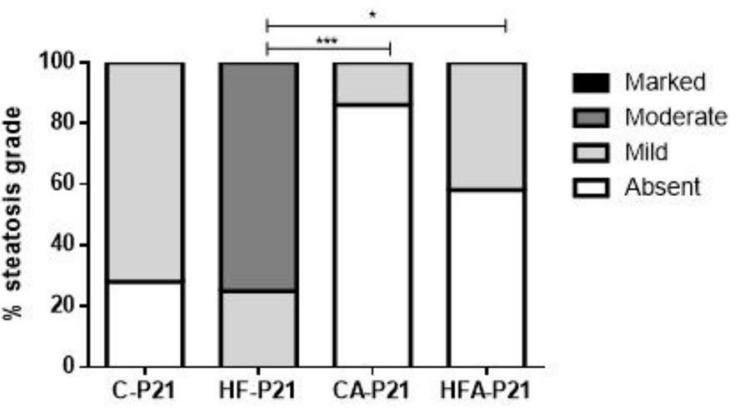

microsteatosis. The images were photographed at a magnification of $400 \times$. Bar Scale $=50 \mu \mathrm{m} ; \mathbf{b}$ Grade of hepatic steatosis of dams $(n=7$ pups per group). Value of $p<0.05$ was considered statistically significant for the Kruskal-Wallis. $*<0.05, * * *<0.005$ 


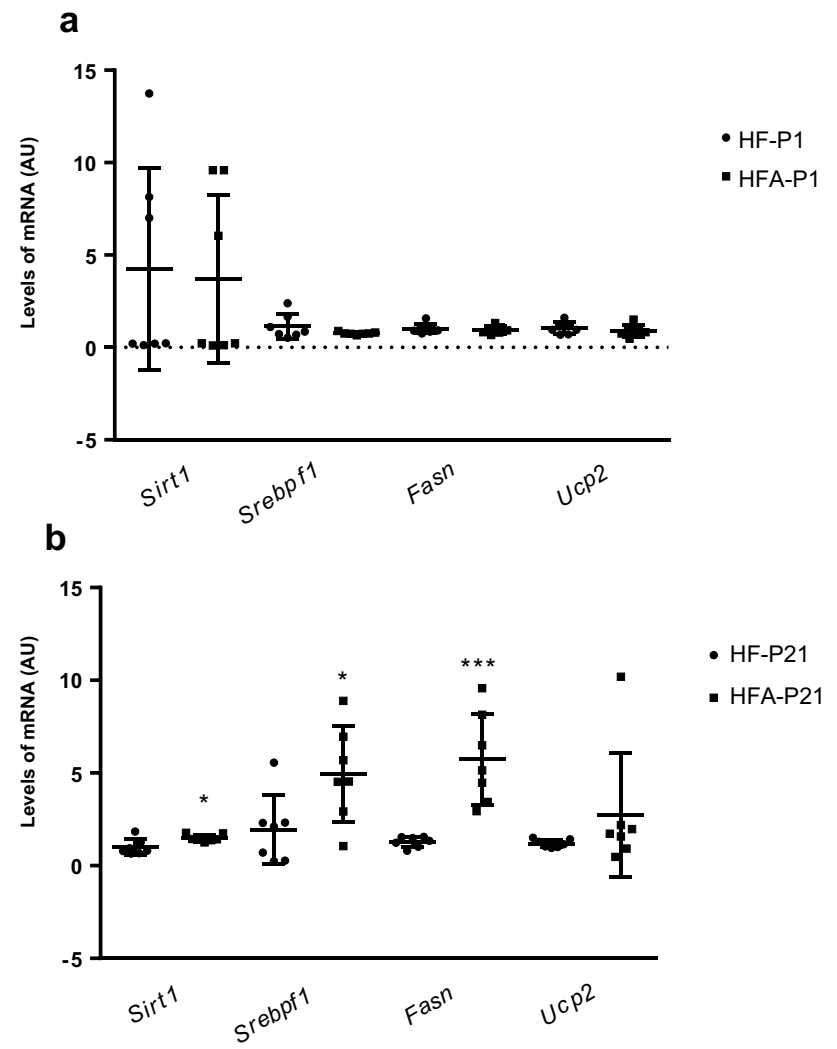

Fig. 5 mRNA abundance for genes related to lipid metabolism in the liver of offspring P1 (a) and offspring P21 (b) relative to beta-2-microglobulin. $H F$ high-fat diet, $H F A$ high-fat açaí diet, Sirt1 sirtuin 1, Srebfl sterol regulatory element-binding transcription factor, Fasn fatty acid synthase, $U c p 2$ uncoupling protein 2 . The results are shown as the mean $\pm \mathrm{SD}$ ( $n=7$ pups per group). Analyses by Student's $t$ test. $* p<0.05 ; * * * p<0.005$

\section{Effect of dietary intervention on protein expression}

SIRT1 and SREBP1 protein expression was analyzed in offspring P1 (Fig. 6a, b) and P21 (Fig. 6c, d) from different maternal diets. No significant differences were observed between the groups. In the same way as it was seen in the dams, the overexpression of Srebfl showed no increase in the expression of the respective proteins.

\section{Discussion}

In the present study, we evaluated the effects of açaí supplementation in combination with a maternal high-fat diet on lipid and liver metabolism of dams and offspring postnatally or post lactation. Our results revealed that, in dams, the highfat diet increased absolute liver weight, serum ALT and AST enzyme activity, hepatic total fat content, cholesterol and triglycerides: changes that are consistent with the development of NAFLD. The addition of açaí in the maternal high-fat diet reduced some of the NAFLD characteristics, including relative liver weight and hepatic fat content, in agreement with previous studies conducted with hyperlipidemic and hypercholesterolemic diet in rats and mice which showed açaí to improve hepatic steatosis and reduce the deleterious effects of lipid excess $[16,17]$. Although these studies were not performed with rodents during gestation or lactation, the results of our study suggest an important role of açaí also in specific physiological states. Regarding the offspring, açaí consumption during gestation and lactation was able to reduce serum cholesterol and degree of steatosis in P21, suggesting this fruit can modify offspring's lipid metabolism, conferring protective effect to the development of hepatic steatosis.

Maternal high-fat diet affected the health of offspring by promoting changes that may trigger the development of metabolic diseases later in life such as diabetes, insulin resistance, obesity, cardiovascular disease and asthma [33]. Studies have described that excess of maternal nutrition during gestation, in combination with a high-fat postnatal diet, is capable of promoting phenotypic alterations, like increased body weight, hyperinsulinemia, hyperglycemia, hypertriglyceridemia and hypercholesterolemia [34, 35]. In contrast, the introduction of foods such as green tea and guarana can improve serum levels of ALT, cholesterol, triglycerides, HDL and glucose in offspring [36, 37]. In our study, the addition of açaí to the maternal high-fat diet reduced serum levels of total cholesterol in offspring $\mathrm{P} 21$ relative to the HF-P21 group. Differently from what was found in the dams, açaí was not able to change the weight and/or fat content in the liver of HF-P21 group. It is possible that the degree of damage caused by the HF diet in the offspring is smaller than in dams and, therefore, the supplementation of açaí in the maternal diet was more effective in mitigating effects at plasma level. In fact, a recent study evaluating the introduction of jussara (a kind of açaí) into a maternal diet enriched with hydrogenated vegetable fat reported a reduction in plasma levels of glucose, total cholesterol and triglycerides in offspring receiving jussara fruit supplementation in a maternal high-fat diet [38]. Another study evaluating the administration of different types of fat (vegetable oil, lard, hydrogenated vegetable oil and fish oil) during gestation and lactation reported that the administration of omega- 3 was able to reduce HDL and serum total cholesterol in dams; whereas in the offspring, there was a reduction in the serum and hepatic levels of triglycerides, as well as a decrease in total cholesterol and free fatty acids [39].

To better understand our results, we evaluated if modulation of the lipid biosynthesis or fatty acids $\beta$-oxidation was responsible for the improvement of NAFLD in dams and possibly in offspring after lactation and gestation. SIRT1 is an important regulator of lipid metabolism in the liver [40]. Fat-rich diets have been shown to reduce 
a
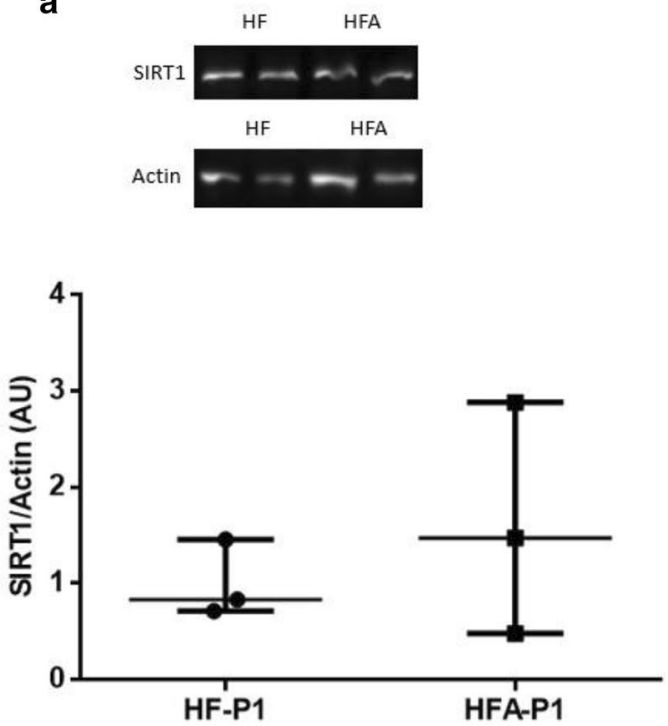

C
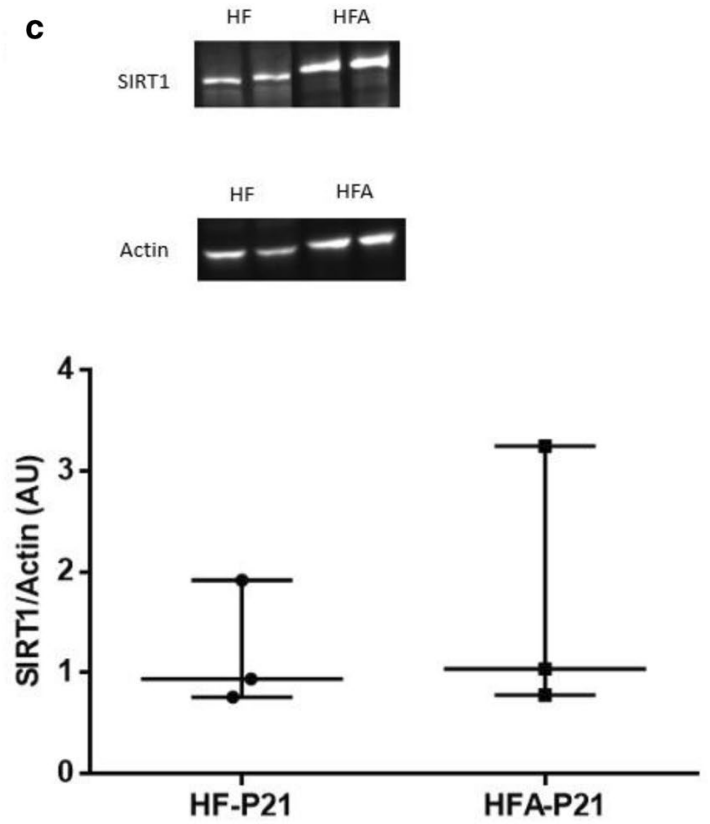

Fig. 6 Western blotting for SIRT1 and SREBP1 of offspring P1 (a, b) and offspring P21 (c, d). Graphs represent data from Western blotting quantification. $H F$ high-fat diet and $H F A$ high-fat supplemented with

the expression of Sirt1 making the liver more susceptible to fat accumulation [41]. This has also been observed in the liver of animals from a maternal high-fat diet, suggesting that the metabolic programming of NAFLD may be involved in the downregulation of Sirt1 [42, 43]. In this regard, the use of compounds capable of activating SIRT1 has emerged as an excellent alternative to attenuate fat accumulation in hepatocytes [44]. In the present work, a trend for increased levels of Sirtl mRNA expression was observed in dams and P1 group after the addition of açaí b
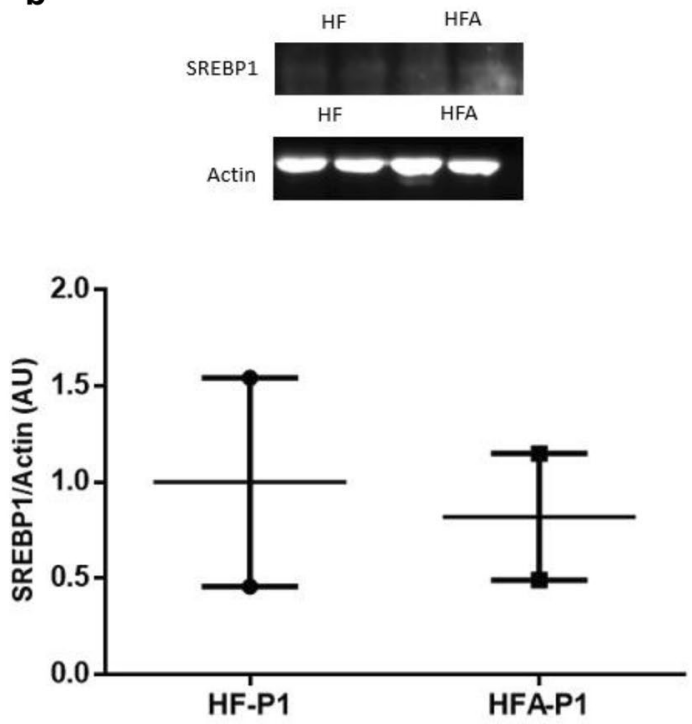

d

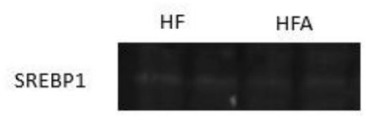

Actin
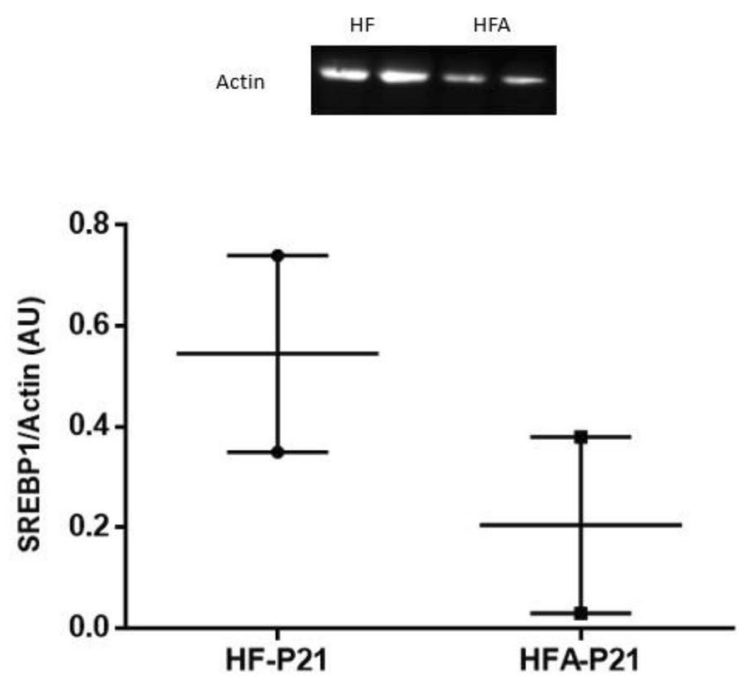

açaí. The data are shown as median and range (minimum and maximum values) ( $n=7$ pups per group). Value of $p<0.05$ was considered statistically significant for the Kruskal-Wallis

to the HF maternal diet, and reached statistical difference in the P21 HFA group ( 0.5 -fold change). However, no changes in protein levels were observed. Açaí is a food that presents high concentration of phenolic compounds, mainly of the class of anthocyanins [22]. We believed that it might be possible to regulate these compounds in the activation of SIRT1 and subsequently in the improvement of NAFLD. It is worth noting that we did not use in this study isolated antioxidant compounds, but the açaí pulp as a food that presents in its composition other dietary 
compounds that can positively affect the lipid metabolism in the liver through the regulation of other ways.

Pathways associated with lipid metabolism are dependent on the expression and activation of SREBP1 and key enzymes of lipid biosynthesis such as FAS and dietary components like PUFA and MUFA fatty acids have been shown to regulate the expression of Srebfl and lipogenic genes, reducing the accumulation of hepatic fat [45]. Therefore, the high proportion of unsaturated fatty acids $(>70 \%)$ present in the lipid fraction of açaí, besides the presence of phenolic compounds, may affect positively lipid metabolism in the liver [22]. In this study, dams and HFA-P21 groups showed an increase in the Srebfl and Fasn mRNA compared to the HF group. Although the results show higher levels of Srebfl mRNA in the HFA group, there appears to be post-translational regulation, since no changes in SREBP1 protein expression were observed in dams and P21. Such results reflect the complexity of lipid metabolism regulation by dietary components. As an example, a study carried out in mice to investigate the effect of different fruits, including açaí, on obesity and metabolic disorders, showed that the groups of animals receiving a high-fat diet supplemented with açaí presented higher glucose and fasting insulin levels compared to groups that received other fruits [46]. In addition, açaí-fed animals showed increased regulation of genes associated with lipid and cholesterol biosynthesis, such as Cidea, Cidec and Anxa2 [47]. In general, the results showed an exacerbation of fatty liver disease by açaí. However, it is important to note that the amount of açaí used in that study was $20 \%$, different from our study that evaluated the effect of supplementation with $2 \%$ açaí pulp. Moreover, in other study, açaí has been shown to have beneficial effects on cholesterol concentration by increasing its elimination by bile via modulation of gene expression for $A b c g 5$ and $A b c g 8$ carriers, as well as up-regulation of the Srebf2 mRNA [48]. This intriguing observation raises another question about how açaí is able to improve the liver fat accumulation. The current study does not provide data to directly answer this question, but other pathways can be altered. It is possible that the presence of fibers in the açaí can increase the excretion of cholesterol and consequently influence on the lipid metabolism, as observed in previous studies with adult rats [48]. In addition, modifications in oxidative metabolism may contribute to the improvement of hepatic lipid accumulation found in this study. Pereira et al., showed that hyperlipidemic rats treated with açaí pulp were able to prevent the oxidation of LDL and to increase the expression of PON1 and ApoA-I, important molecules related oxidative stress and lipid metabolism [24, 49, 50]. However, this study it was not conducted in a specific state such as gestation and lactation. Other hand, unsaturated fatty acids may provide an increase in the expression and activity of the LDL receptors in the liver [51]. PUFAs found in high amounts in açaí can act as potent activators of the peroxisome proliferator-activated receptor family (PPARs) that regulate other genes involved in lipid metabolism.

To verify the ability of açaí to increase lipid oxidation and thus improve lipid accumulation, levels of $U c p 2$ mRNA were assessed. No differences were found in the liver of dams and P1. Regarding the offspring P21, although the Ucp2 gene expression was $166 \%$ higher, no statistically significant difference was observed. In view of the role of UCP2 in reducing ROS and promoting efficient mitochondrial oxidation, an increase in $U c p 2$ expression could suggest an increase in the beta oxidation of fatty acids in P21. In fact, a study evaluating the effect of açaí aqueous extract on hepatic steatosis in adults mice showed an increase in carnitine-palmitoyl transferase (CPT-I), a key enzyme in the entry of fatty acids to $\beta$-oxidation [23]. In addition, uncoupling proteins also carry the transport of fatty acid anions and lipoperoxide anions through the inner mitochondrial membrane [17]. This mechanism can be interpreted as a way to relieve the matrix of lipids excess. Therefore, UCP2 could also act in the protection of the liver against hepatocellular lipotoxicity [52]. One hypothesis is that the presence of bioactive compounds in açaí confers a beneficial effect in the fat liver accumulation through the reduction of oxidative stress, since açaí is rich in polyphenols and anthocyanins, and regulation of the production of ROS alleviates accumulation of fat droplets in the liver, as observed in our study with an improvement in fat liver content and grade of steatosis. A study by Chen et al. (2018), using sugar kefir, demonstrated a reduction in lipid peroxidation levels and increased the activity of superoxide dismutase (SOD) and catalase (CAT) enzymes [53]. The mechanisms involve the activation of NRF2, an important regulator of oxidative stress and the production of ROS [54, 55]. However, future studies involving redox metabolism need to be performed.

Açaí has also a high fiber content (30\%), of which more than $20 \%$ is of the soluble type [22]. Fibers are known to promote a lower intestinal absorption of cholesterol from the diet and, consequently, increase the release of this sterol through chylomicrons [56]. Dietary fiber has been shown to be responsible for the increased biliary excretion in rats, thereby reducing serum cholesterol and blocking the enterohepatic circulation preventing reuse of bile acids by the liver [57]. In addition, dietary fibers seem to act indirectly in the expression of genes involved in the metabolism of hepatic cholesterol through secondary signals generated by metabolites produced in the intestine during fermentation [58]; however, this mechanism has not yet been fully elucidated. It is possible that the antioxidant effect of açaí can act directly on the pathways of oxidative stress, neutralizing free radicals and softening the damage caused by excess of lipids. It is important to remember that the açaí used in this study is a whole fruit. It is difficult to define which compound is 
responsible for the improvements observed in dams and offspring: a synergism between the different macro and micronutrients, as well as phytochemicals present in açaí may be responsible.

Currently, due to the increase in NAFLD in the pediatric population and the high prevalence of maternal obesity, several studies have emerged to understand how the maternal high-fat diet is able to "programming" the fetal liver and predispose the organism to early metabolic disorders. Nevertheless, studies that report the effects of combining a high-fat diet and foods or bioactive compounds into the development of NAFLD through molecular pathways are still limited. Epigenetic studies become important in metabolic programming models, since post-translation modifications in mRNA as repression or degradation may be occurring via microRNAs [59]. In addition, the increase or reduction of methylation in gene promoting regions is also related to regulation in gene expression [60]. Recent work had reported alterations in epigenetic mechanisms and possible regulation through bioactive compounds [61]. Furthermore, it is known that NAFLD is a complex disease that involves, besides lipid metabolism, changes in the insulin cascade, which were not evaluated in this study. The acetylated/deacetylated fractions of the SREBP1 transcription factor were not evaluated, which could promote a more accurate response in relation to the increase in Sirt1 expression and its effect on SREBP1. We have observed an improvement in the liver lipids of the HFA dams. We do not believe that this effect was in detriment of the offspring once the total and relative liver weights (HFA-P1 and HFA-P21), as well as the total serum cholesterol were reduced in HFA-P21. High-fat diet promotes changes in lipid metabolism involving the crosstalk between liver and adipose tissue and this could explain the alterations in the dams lipid liver metabolism; however, one of the limitations of the study is the lack of data on the adipose tissue of dams and offspring. Although modifications in adipose tissue have not been evaluated, our work contains valuable data on açaí supplementation during specific physiological periods, such as gestation and lactation. Future studies could be conducted to evaluate the effect of açaí on lipid metabolism of adipose tissue.

In summary, the introduction of açaí to the maternal high-fat diet was able to exert a beneficial effect on the lipid metabolism of the dams, reducing the accumulation of hepatic fat, liver levels of total cholesterol and degree of steatosis. Açaí effects were observed in the offspring at serum level, suggesting that the hepatic damage caused by the high-fat maternal diet in offspring could be delayed with the introduction of foods rich in bioactive compounds and, therefore, have beneficial effects on health. More studies are needed to better understand the mechanisms involved to justify the effects of açaí supplementation during gestation and lactation.
Acknowledgements The authors are grateful to the Jair Pastor Mota and Laboratory of Experimental Nutrition for technical support and supply of animals, Dr Daniela Pala (UFOP, Brazil), Dr Carla Teixeira Silva (UFOP, Brazil), MSc. Miliane Fagundes (UFOP, Brazil), MSc. Ana Maria Viana (UFOP, Brazil), MSc. Talita Magalhães (UFOP, Brazil), MSc. Raiana Souza e Silva (UFOP, Brazil), Maraisa Porfirio (UFOP, Brazil) and Daniel de Souza Paula (UFOP, Brazil) for helping with the animal handling. We thank Professor Dr Maria Terezinha Bahia (UFOP, Brazil) who provided laboratory reagents to perform biochemistry analysis, and Dr Gemma Barron (RGU, UK) for help with gene expression and western blotting experiments.

Funding This research was supported by Federal University of Ouro Preto (UFOP, Minas Gerais, Brazil), Fundação de Amparo a Pesquisa do Estado de Minas Gerais (FAPEMIG, Minas Gerais, Brazil), Coordenação de Aperfeiçoamento de Pessoal de Nível Superior (CAPES) from Brazilian government (P.O.B. scholarship) and Robert Gordon University (Aberdeen, Scotland, United Kingdom).

\section{Compliance with ethical standards}

Conflict of interest The authors declare that they have no conflict of interest.

\section{References}

1. Brunt EM (2010) Pathology of nonalcoholic fatty liver disease. Nat Rev Gastroenterol Hepatol 7(4):195-203. https://doi. org/10.1038/nrgastro.2010.21

2. Stewart MS, Heerwagen MJ, Friedman JE (2013) Developmental programming of pediatric nonalcoholic fatty liver disease: redefining the "first hit". Clin Obstet Gynecol 56(3):577-590. https://doi. org/10.1097/GRF.0b013e3182a09760

3. Li M, Sloboda DM, Vickers MH (2011) Maternal obesity and developmental programming of metabolic disorders in offspring: evidence from animal models. Exp Diabetes Res 2011:592408. https://doi.org/10.1155/2011/592408

4. Hochberg Z, Feil R, Constancia M, Fraga M, Junien C, Carel JC, Boileau P, Le Bouc Y, Deal CL, Lillycrop K, Scharfmann R, Sheppard A, Skinner M, Szyf M, Waterland RA, Waxman DJ, Whitelaw E, Ong K, Albertsson-Wikland K (2011) Child health, developmental plasticity, and epigenetic programming. Endocr Rev 32(2):159-224. https://doi.org/10.1210/er.2009-0039

5. Fleming TP, Eckert JJ, Denisenko O (2017) The role of maternal nutrition during the periconceptional period and its effect on offspring phenotype. Adv Exp Med Biol 1014:87-105. https://doi. org/10.1007/978-3-319-62414-3_5

6. Williams L, Seki Y, Vuguin PM (1842) Charron MJ (2014) Animal models of in utero exposure to a high fat diet: a review. Biochim Biophys Acta 3:507-519. https://doi.org/10.1016/j.bbadi s.2013.07.006

7. Speakman J, Hambly C, Mitchell S, Krol E (2008) The contribution of animal models to the study of obesity. Lab Anim 42(4):413-432. https://doi.org/10.1258/la.2007.006067

8. Hughes AN, Oxford JT (2014) A lipid-rich gestational diet predisposes offspring to nonalcoholic fatty liver disease: a potential sequence of events. Hepat Med 6:15-23. https://doi.org/10.2147/ HMER.S57500

9. Sacconnay L, Carrupt PA, Nurisso A (2016) Human sirtuins: structures and flexibility. J Struct Biol 196(3):534-542. https:// doi.org/10.1016/j.jsb.2016.10.008

10. Ponugoti B, Kim DH, Xiao Z, Smith Z, Miao J, Zang M, Wu SY, Chiang CM, Veenstra TD, Kemper JK (2010) SIRT1 deacetylates 
and inhibits SREBP-1C activity in regulation of hepatic lipid metabolism. J Biol Chem 285(44):33959-33970. https://doi. org/10.1074/jbc.M110.122978

11. Eberle D, Hegarty B, Bossard P, Ferre P, Foufelle F (2004) SREBP transcription factors: master regulators of lipid homeostasis. Biochimie 86(11):839-848. https://doi.org/10.1016/j.bioch i. 2004.09 .018

12. Suter MA, Chen A, Burdine MS, Choudhury M, Harris RA, Lane RH, Friedman JE, Grove KL, Tackett AJ, Aagaard KM (2012) A maternal high-fat diet modulates fetal SIRT1 histone and protein deacetylase activity in nonhuman primates. FASEB J 26(12):5106-5114. https://doi.org/10.1096/fj.12-212878

13. McCurdy CE, Bishop JM, Williams SM, Grayson BE, Smith MS, Friedman JE, Grove KL (2009) Maternal high-fat diet triggers lipotoxicity in the fetal livers of nonhuman primates. J Clin Invest 119(2):323-335. https://doi.org/10.1172/JCI32661

14. Bruce KD, Cagampang FR, Argenton M, Zhang J, Ethirajan PL, Burdge GC, Bateman AC, Clough GF, Poston L, Hanson MA, McConnell JM, Byrne CD (2009) Maternal high-fat feeding primes steatohepatitis in adult mice offspring, involving mitochondrial dysfunction and altered lipogenesis gene expression. Hepatology 50(6):1796-1808. https://doi.org/10.1002/hep.23205

15. Rolo AP, Teodoro JS, Palmeira CM (2012) Role of oxidative stress in the pathogenesis of nonalcoholic steatohepatitis. Free Radic Biol Med 52(1):59-69. https://doi.org/10.1016/j.freeradbio med.2011.10.003

16. Nedergaard J, Cannon B (2003) The 'novel' 'uncoupling' proteins UCP2 and UCP3: what do they really do? Pros and cons for suggested functions. Exp Physiol 88(1):65-84

17. Baffy $\mathrm{G}$ (2005) Uncoupling protein-2 and non-alcoholic fatty liver disease. Front Biosci 10:2082-2096

18. Pan MH, Lai CS, Tsai ML, Ho CT (2014) Chemoprevention of nonalcoholic fatty liver disease by dietary natural compounds. Mol Nutr Food Res 58(1):147-171. https://doi.org/10.1002/ mnfr.201300522

19. Tanaka M, Kita T, Yamasaki S, Kawahara T, Ueno Y, Yamada M, Mukai Y, Sato S, Kurasaki M, Saito T (2017) Maternal resveratrol intake during lactation attenuates hepatic triglyceride and fatty acid synthesis in adult male rat offspring. Biochem Biophys Rep 9:173-179. https://doi.org/10.1016/j.bbrep.2016.12.011

20. Tiao MM, Lin YJ, Yu HR, Sheen JM, Lin IC, Lai YJ, Tain YL, Huang LT, Tsai CC (2018) Resveratrol ameliorates maternal and post-weaning high-fat diet-induced nonalcoholic fatty liver disease via renin-angiotensin system. Lipids Health Dis 17(1):178. https://doi.org/10.1186/s12944-018-0824-3

21. Chung S, Yao H, Caito S, Hwang JW, Arunachalam G, Rahman I (2010) Regulation of SIRT1 in cellular functions: role of polyphenols. Arch Biochem Biophys 501(1):79-90. https://doi. org/10.1016/j.abb.2010.05.003

22. Schauss AG, Wu X, Prior RL, Ou B, Patel D, Huang D, Kababick JP (2006) Phytochemical and nutrient composition of the freezedried amazonian palm berry, Euterpe oleraceae mart. (acai). J Agric Food Chem 54(22):8598-8603. https://doi.org/10.1021/ jf060976g

23. Guerra JFC, Maciel PS, Abreu ICME, Pereira RR, Silva M, Cardoso LM, Pinheiro-Sant'Ana HM, Lima WG, Silva ME, Pedrosa ML (2015) Dietary açai attenuates hepatic steatosis via adiponectin-mediated effects on lipid metabolism in high-fat diet mice. J Funct Foods 14:192-202. https://doi.org/10.1016/j. jff.2015.01.025

24. Pereira RR, de Abreu IC, Guerra JF, Lage NN, Lopes JM, Silva M, de Lima WG, Silva ME, Pedrosa ML (2016) Acai (Euterpe oleracea Mart.) upregulates paraoxonase 1 gene expression and activity with concomitant reduction of hepatic steatosis in high-fat diet-fed rats. Oxid Med Cell Longev 2016:8379105. https://doi. org/10.1155/2016/8379105
25. George S, Brat P, Alter P, Amiot MJ (2005) Rapid determination of polyphenols and vitamin $\mathrm{C}$ in plant-derived products. $\mathrm{J}$ Agric Food Chem 53(5):1370-1373. https://doi.org/10.1021/ jf048396b

26. Giusti MM, Wrolstad RE (2001) Characterization and Measurement of Anthocyanins by UV-Visible Spectroscopy. Curr Protoc Food Anal Chem 1:F1.2.1-F1.2.13. https://doi.org/10.1002/04711 42913.faf0102s00

27. Reeves PG, Nielsen FH, Fahey GC Jr (1993) AIN-93 purified diets for laboratory rodents: final report of the American Institute of Nutrition ad hoc writing committee on the reformulation of the AIN-76A rodent diet. J Nutr 123(11):1939-1951. https://doi. org/10.1093/jn/123.11.1939

28. Burgueno AL, Cabrerizo R, Gonzales Mansilla N, Sookoian S, Pirola CJ (2013) Maternal high-fat intake during pregnancy programs metabolic-syndrome-related phenotypes through liver mitochondrial DNA copy number and transcriptional activity of liver PPARGC1A. J Nutr Biochem 24(1):6-13. https://doi. org/10.1016/j.jnutbio.2011.12.008

29. Guerra JF, Magalhaes CL, Costa DC, Silva ME, Pedrosa ML (2011) Dietary acai modulates ROS production by neutrophils and gene expression of liver antioxidant enzymes in rats. J Clin Biochem Nutr 49(3):188-194. https://doi.org/10.3164/jcbn.11-02

30. Padilha PC, Rocha HF, Alves N, Peres WAF (2010) Prevalence of nonalcoholic fatty liver disease in obese children and adolescents: a systematic review. Rev Paul Pediatr 28(4):387-393. https://doi. org/10.1590/S0103-05822010000400016

31. Folch J, Lees M, Sloane Stanley GH (1957) A simple method for the isolation and purification of total lipides from animal tissues. J Biol Chem 226(1):497-509

32. Brunt EM (2016) Nonalcoholic fatty liver disease: pros and cons of histologic systems of evaluation. Int J Mol Sci 17(1):97. https ://doi.org/10.3390/ijms17010097

33. Godfrey KM, Reynolds RM, Prescott SL, Nyirenda M, Jaddoe VW, Eriksson JG, Broekman BF (2017) Influence of maternal obesity on the long-term health of offspring. Lancet Diabetes Endocrinol 5(1):53-64. https://doi.org/10.1016/S2213 -8587(16)30107-3

34. Desai M, Jellyman JK, Han G, Beall M, Lane RH, Ross MG (2014) Maternal obesity and high-fat diet program offspring metabolic syndrome. Am J Obstet Gynecol 211 (3):237e231. https:// doi.org/10.1016/j.ajog.2014.03.025

35. Renault KM, Carlsen EM, Norgaard K, Nilas L, Pryds O, Secher NJ, Cortes D, Jensen JE, Olsen SF, Halldorsson TI (2015) Intake of carbohydrates during pregnancy in obese women is associated with fat mass in the newborn offspring. Am J Clin Nutr 102(6):1475-1481. https://doi.org/10.3945/ajcn.115.110551

36. Hachul ACL, Boldarine VT, Neto NIP, Moreno MF, Ribeiro EB, OdN CM, Oyama LM (2018) Maternal consumption of green tea extract during pregnancy and lactation alters offspring's metabolism in rats. PLoS ONE 13(7):e0199969. https://doi.org/10.1371/ journal.pone.0199969

37. Lima NDS, Caria C, Gambero A, Ribeiro ML (2018) The effect of Guarana (Paullinia cupana) on metabolic and inflammatory parameters in adult male mice programmed by maternal obesity. Eur J Nutr https://doi.org/10.1007/s00394-018-1686-1

38. Argentato PP, Morais CA, Santamarina AB, César HC, Estadella D, Rosso VV, Pisani LP (2017) Jussara (Euterpe edulis Mart.) supplementation during pregnancy and lactation modulates UCP-1 and inflammation biomarkers induced by trans-fatty acids in the brown adipose tissue of offspring. Clin Nutr Exp 12:50-65. https://doi.org/10.1016/j.yclnex.2016.12.002

39. Mennitti LV, Oyama LM, Santamarina AB, Nascimento OD, Pisani LP (2018) Influence of maternal consumption of different types of fatty acids during pregnancy and lactation on lipid and glucose metabolism of the 21-day-old male offspring in rats. 
Prostaglandins Leukot Essent Fatty Acids 135:54-62. https://doi. org/10.1016/j.plefa.2018.07.001

40. Kemper JK, Choi SE, Kim DH (2013) Sirtuin 1 deacetylase: a key regulator of hepatic lipid metabolism. Vitam Horm 91:385-404. https://doi.org/10.1016/B978-0-12-407766-9.00016-X

41. Deng XQ, Chen LL, Li NX (2007) The expression of SIRT1 in nonalcoholic fatty liver disease induced by high-fat diet in rats. Liver Int 27(5):708-715. https://doi.org/10.111 1/j.1478-3231.2007.01497.x

42. Nguyen LT, Chen H, Pollock CA, Saad S (2016) Sirtuins-mediators of maternal obesity-induced complications in offspring? FASEB J 30(4):1383-1390. https://doi.org/10.1096/fj.15-280743

43. Borengasser SJ, Kang P, Faske J, Gomez-Acevedo H, Blackburn ML, Badger TM, Shankar K (2014) High fat diet and in utero exposure to maternal obesity disrupts circadian rhythm and leads to metabolic programming of liver in rat offspring. PLoS ONE 9(1):e84209. https://doi.org/10.1371/journal.pone.0084209

44. Alberdi G, Rodriguez VM, Macarulla MT, Miranda J, Churruca I, Portillo MP (2013) Hepatic lipid metabolic pathways modified by resveratrol in rats fed an obesogenic diet. Nutrition 29(3):562 567. https://doi.org/10.1016/j.nut.2012.09.011

45. Jump DB, Tripathy S, Depner CM (2013) Fatty acid-regulated transcription factors in the liver. Annu Rev Nutr 33:249-269. https ://doi.org/10.1146/annurev-nutr-071812-161139

46. Heyman L, Axling U, Blanco N, Sterner O, Holm C, Berger K (2014) Evaluation of Beneficial Metabolic Effects of Berries in High-Fat Fed C57BL/6J Mice. J Nutr Metab 2014:12. https://doi. org/10.1155/2014/403041

47. Heyman-Linden L, Seki Y, Storm P, Jones HA, Charron MJ, Berger K, Holm C (2016) Berry intake changes hepatic gene expression and DNA methylation patterns associated with highfat diet. J Nutr Biochem 27:79-95. https://doi.org/10.1016/j.jnutb io.2015.08.022

48. de Souza MO, Souza ESL, de Brito Magalhaes CL, de Figueiredo BB, Costa DC, Silva ME, Pedrosa ML (2012) The hypocholesterolemic activity of acai (Euterpe oleracea Mart.) is mediated by the enhanced expression of the ATP-binding cassette, subfamily G transporters 5 and 8 and low-density lipoprotein receptor genes in the rat. Nutr Res 32(12):976-984. https://doi.org/10.1016/j.nutre s.2012.10.001

49. Karavia EA, Papachristou DJ, Liopeta K, Triantaphyllidou IE, Dimitrakopoulos O, Kypreos KE (2012) Apolipoprotein A-I modulates processes associated with diet-induced nonalcoholic fatty liver disease in mice. Mol Med 18:901-912. https://doi. org/10.2119/molmed.2012.00113

50. Garcia-Heredia A, Kensicki E, Mohney RP, Rull A, Triguero I, Marsillach J, Tormos C, Mackness B, Mackness M, Shih DM, Pedro-Botet J, Joven J, Saez G, Camps J (2013) Paraoxonase-1 deficiency is associated with severe liver steatosis in mice fed a high-fat high-cholesterol diet: a metabolomic approach. J Proteome Res 12(4):1946-1955. https://doi.org/10.1021/pr400050u
51. Fukushima M, Nakano M, Morii Y, Ohashi T, Fujiwara Y, Sonoyama K (2000) Hepatic LDL receptor mRNA in rats is increased by dietary mushroom (Agaricus bisporus) fiber and sugar beet fiber. J Nutr 130(9):2151-2156. https://doi.org/10.1093/jn/130.9.2151

52. Cortez-Pinto H, Machado MV (2009) Uncoupling proteins and non-alcoholic fatty liver disease. J Hepatol 50(5):857-860. https ://doi.org/10.1016/j.jhep.2009.02.019

53. Chen YT, Lin YC, Lin JS, Yang NS, Chen MJ (2018) Sugary Kefir strain lactobacillus mali APS1 ameliorated hepatic steatosis by regulation of SIRT-1/Nrf-2 and Gut microbiota in rats. Mol Nutr Food Res 62(8):e1700903. https://doi.org/10.1002/mnfr.20170 0903

54. Bayele HK, Debnam ES, Srai KS (2016) Nrf2 transcriptional derepression from Keap1 by dietary polyphenols. Biochem Biophys Res Commun 469(3):521-528. https://doi.org/10.1016/j. bbrc.2015.11.103

55. Nguyen T, Nioi P, Pickett CB (2009) The Nrf2-antioxidant response element signaling pathway and its activation by oxidative stress. J Biol Chem 284(20):13291-13295. https://doi. org/10.1074/jbc.R900010200

56. Anderson JW, Baird P, Davis RH Jr, Ferreri S, Knudtson M, Koraym A, Waters V, Williams CL (2009) Health benefits of dietary fiber. Nutr Rev 67(4):188-205. https://doi.org/10.111 1/j.1753-4887.2009.00189.x

57. Garcia-Diez F, Garcia-Mediavilla V, Bayon JE, Gonzalez-Gallego J (1996) Pectin feeding influences fecal bile acid excretion, hepatic bile acid and cholesterol synthesis and serum cholesterol in rats. $\mathrm{J}$ Nutr 126(7):1766-1771. https://doi.org/10.1093/jn/126.7.1766

58. Caz V, Gil-Ramirez A, Largo C, Tabernero M, Santamaria M, Martin-Hernandez R, Marin FR, Reglero G, Soler-Rivas C (2015) Modulation of cholesterol-related gene expression by dietary fiber fractions from edible mushrooms. J Agric Food Chem 63(33):7371-7380. https://doi.org/10.1021/acs.jafc.5b02942

59. Simino LAP, de Fante T, Fontana MF, Borges FO, Torsoni MA, Milanski M, Velloso LA, Torsoni AS (2017) Lipid overload during gestation and lactation can independently alter lipid homeostasis in offspring and promote metabolic impairment after new challenge to high-fat diet. Nutr Metab Lond 14:16. https://doi. org/10.1186/s12986-017-0168-4

60. Pirola CJ, Gianotti TF, Burgueno AL, Rey-Funes M, Loidl CF, Mallardi P, Martino JS, Castano GO, Sookoian S (2013) Epigenetic modification of liver mitochondrial DNA is associated with histological severity of nonalcoholic fatty liver disease. Gut 62(9):1356-1363. https://doi.org/10.1136/gutjnl-2012-302962

61. Baselga-Escudero L, Pascual-Serrano A, Ribas-Latre A, Casanova E, Salvado MJ, Arola L, Arola-Arnal A, Blade C (2015) Longterm supplementation with a low dose of proanthocyanidins normalized liver miR-33a and miR-122 levels in high-fat diet-induced obese rats. Nutr Res 35(4):337-345. https://doi.org/10.1016/j. nutres.2015.02.008 